\title{
Psychiatric comorbidity among alcohol-dependent individuals seeking treatment at the Alcohol Rehabilitation Unit, Stikland Hospital
}

\begin{tabular}{|c|c|}
\hline \multicolumn{2}{|c|}{$\begin{array}{l}\text { Authors: } \\
\text { Charnotte M. Gabriels }{ }^{1} \\
\text { Muiruri Macharia } \\
\text { Lize Weich }^{1}\end{array}$} \\
\hline \multicolumn{2}{|c|}{$\begin{array}{l}\text { Affiliations: } \\
\text { }{ }^{1} \text { Department of Psychiatry, } \\
\text { Faculty of Medicine and } \\
\text { Health Sciences, Stellenbosch } \\
\text { University, Cape Town, } \\
\text { South Africa }\end{array}$} \\
\hline \multicolumn{2}{|c|}{$\begin{array}{l}\text { Corresponding author: } \\
\text { Lize Weich, } \\
\text { lizew@sun.ac.za }\end{array}$} \\
\hline \multicolumn{2}{|c|}{$\begin{array}{l}\text { Dates: } \\
\text { Received: } 19 \text { Mar. } 2018 \\
\text { Accepted: } 29 \text { Oct. } 2018 \\
\text { Published: } 16 \text { Apr. } 2019\end{array}$} \\
\hline \multicolumn{2}{|c|}{$\begin{array}{l}\text { How to cite this article: } \\
\text { Gabriels CM, Macharia M, } \\
\text { Weich L. Psychiatric } \\
\text { comorbidity among } \\
\text { alcohol-dependent } \\
\text { individuals seeking treatment } \\
\text { at the Alcohol Rehabilitation } \\
\text { Unit, Stikland Hospital. S Afr J } \\
\text { Psychiat. 2019;25(0), a1218. } \\
\text { https://doi.org/10.4102/ } \\
\text { sajpsychiatry.v25i0.1218 }\end{array}$} \\
\hline \multicolumn{2}{|c|}{$\begin{array}{l}\text { Copyright: } \\
\text { (c) 2019. The Authors. } \\
\text { Licensee: AOSIS. This v } \\
\text { is licensed under the } \\
\text { Creative Commons } \\
\text { Attribution License. }\end{array}$} \\
\hline \multicolumn{2}{|l|}{ Read online: } \\
\hline 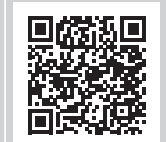 & $\begin{array}{l}\text { Scan this QR } \\
\text { code with your } \\
\text { smart phone or } \\
\text { mobile device } \\
\text { to read online. }\end{array}$ \\
\hline
\end{tabular}

Background: International studies have found high rates of psychiatric comorbidity among patients with alcohol use disorders (AUDs) and highlighted the clinical and prognostic implications of this finding. There is a paucity of information with regard to the extent of this problem within the South African context.

Aim: The aim of this study was to investigate the prevalence of psychiatric comorbidity (DSM IV-TR) in treatment-seeking, alcohol-dependent South Africans.

Setting: This study was conducted at the Alcohol Rehabilitation Unit (ARU), Stikland Hospital, Western Cape.

Methods: This cross-sectional study was conducted over a 6-month period. The MiniInternational Neuropsychiatric Interview (MINI, version 5) was used to assess psychiatric comorbidity in 101 (male, $n=65 ; 64.5 \%$ ) alcohol-dependent patients. Interviews were conducted after the first week of admission to ward 13.

Results: Most participants $(n=63,62.4 \%)$ had a co-occurring psychiatric disorder, the most common being major depressive $(n=30,29.7 \%)$ and anxiety disorders $(n=43,42.6 \%)$. Of the anxiety disorders, agoraphobia without a history of panic disorder $(n=10,9.9 \%)$ and social phobia $(n=10,9.9 \%)$ occurred most frequently, followed by generalised anxiety disorder $(n=9,8.9 \%)$ and post-traumatic stress disorder $(n=9,8.9 \%)$. Thirteen patients $(13 \%)$ had a comorbid substance use disorder other than AUD.

Conclusion: The prevalence of psychiatric comorbidity at this unit is high, especially among female patients. The findings emphasise a need to thoroughly assess patients and provide treatment and personnel who can manage the complex needs of a dual diagnosis patient population.

Keywords: Alcohol use disorder; Alcoholism; Alcohol dependence; Alcohol addiction; Comorbidity; Dual diagnosis; Psychiatric illness.

\section{Introduction}

Psychiatric comorbidity, the co-occurrence of multiple mental disorders in an individual, is a well-established phenomenon in people with alcohol use disorders (AUDs). ${ }^{1,2,3}$ Persons with AUD are more likely to have additional psychiatric disorders, the most frequent being mood, anxiety and substance use disorders. ${ }^{4,5}$ Although the precise aetiology is not clear, Koob proposed that the heavy use of alcohol leads to alterations in brain transmitters and hormonal systems which, in turn, might contribute to the development of common psychiatric disorders. ${ }^{6}$ Another explanation for psychiatric comorbidity among patients with AUD is that the psychosocial stressors (legal, financial, interpersonal relationship difficulties) related to alcohol dependence may also predispose the individuals to psychiatric problems. ${ }^{7}$

The presence of additional disorders has implications for the patient, clinician and service provision. Patients with dual diagnoses often have poorer response to treatment, higher rates of dropout, relapse and readmission, and may present with symptoms that are more severe and persistent than other patients. ${ }^{8,9}$ In addition, these patients are generally more impaired and suicidal, have difficulties in maintaining relationships and stable financial profile, have more conflicts with the law and generally make more use of healthcare services.9,10,11,12 Therefore, an understanding of psychiatric complications in patients with AUD is important if effective, integrated treatment addressing both comorbidities is to be successfully implemented. 
South Africa has a relatively high (30.0\%) lifetime prevalence of mental illness, with the Western Cape having the highest rate $(39.0 \%)$ among the nine provinces. ${ }^{13,14,15}$ Williams et al. reported that the most prevalent categories of lifetime disorders were anxiety $(15.8 \%)$, substance use (13.3\%) and mood disorders (9.8\%). ${ }^{13}$ Studies looking at both population and clinical samples in the province have also confirmed the association between psychiatric comorbidity and substance use disorders. ${ }^{16,17,18,19}$

Using results from the South African Stress and Health household survey, Saban et al. found significant associations between substance use and mood and anxiety disorders compared to persons who did not use substances. ${ }^{16}$ Furthermore, when looking at alcohol use, $17.7 \%$ of patients with alcohol use met criteria for a lifetime anxiety disorder and $8.2 \%$ for a 12 -month anxiety disorder, while $11.8 \%$ met criteria for a lifetime major depression and $6.1 \%$ for a 12-month major depression. ${ }^{16}$ Saban et al. found high rates of antisocial personality and conduct disorders among substance using adolescents and young adults in inpatient treatment, ${ }^{17}$ and Weich et al. found that $51.0 \%$ of psychiatric inpatients had a secondary substance use disorder. ${ }^{18}$ Abler et al. investigated alcohol use, post-traumatic stress disorder and depressive symptoms in South African women who attended alcohol-serving venues and described the complex interplay between these three problems. ${ }^{19}$

High rates of psychiatric comorbidity can, therefore, be expected in patients with AUD, yet we could not find any South African reports on the extent of the problem in this patient population. Therefore, the aim of this study was to examine psychiatric comorbidity at the province's only public alcohol rehabilitation unit (ARU).

\section{Research methods and design Study design}

This cross-sectional study was conducted over a 6-month period, between August 2015 and January 2016.

\section{Study setting}

This study was conducted at the ARU, Stikland Hospital, a tertiary psychiatric facility in Western Cape, South Africa.

\section{Population and sampling}

The study sample was drawn from inpatients at the ARU. A total of 159 patients were admitted during the study period. The primary investigator attended the unit weekly and screened all admissions in their second week of treatment for inclusion. Inclusion criteria were that participants had to be at least 18 years of age, clinically stable, willing to give consent and literate enough to complete the questionnaire. We excluded individuals who did not meet eligibility criteria or were unwilling to participate, as well as those who were not present in the unit at the time of screening. In instances where patients were readmitted during the study period, we collected data from only the first admission. A total of 101 patients were recruited.

\section{Data collection}

Data were collected from participants after the first week of admission to limit interference from withdrawal symptoms. A data collection sheet was used to record socio-demographic, admission and general health details. The English version of the Mini-International Neuropsychiatric Interview (MINI, version 5) was used to evaluate previous and current psychiatric disorders. ${ }^{20}$

\section{Data analysis}

Continuous variables were summarised as means and standard deviations, while categorical variables were summarised as count and percentages. Comparisons between variables were made using the $t$-test and Chisquare test for continuous and categorical variables, respectively. Data were analysed using the Statistical Package for Social Sciences version 22 (SPSS 22), and the level of statistical significance was set at $p<0.05$.

\section{Ethical consideration}

This study was approved by the Health Research Ethics Committee of Stellenbosch University, Cape Town, South Africa (HREC\# S14/08/163). All participants included in the analysis gave written informed consent and were treated according to locally and internationally accepted ethical guidelines. Refusal to participate in this study did not impact their treatment.

\section{Results \\ Sample demographics}

Of all the participants who were recruited $(N=101), 65$ (64.4\%) were men and the sample had a mean age of 42.5 (standard deviation [s.d.] = 9.9) years $($ Table 1$)$. The vast majority were single or living alone $(84.2 \%)$, educated to high school level (grades $8-12 ; n=73,72.3 \%$ ) and unemployed $(n=67,66.3 \%)$.

\section{Alcohol and drug use}

Long-term alcohol use was common in the study population, with $79(78.2 \%)$ patients reporting that they had been drinking excessively for more than 12 months. Most participants $(n=47,46.5 \%)$ reported drinking a combination of beer, wine and spirits. Other participants drank beer $(n=24,24.8 \%)$ or wine $(n=19,18.8 \%)$ as their preferred beverage. Seventy-nine participants (78.2\%) smoked cigarettes or used tobacco. The drug most experimented with was cannabis $(n=35,34.65 \%)$ followed by a combination of drugs $(n=10,9.90 \%)$, stimulants $(n=$ $6,5.94 \%)$, mandrax $(n=1,1 \%)$, heroin $(n=1,1 \%)$ and prescription medication $(n=1,1 \%)$. 


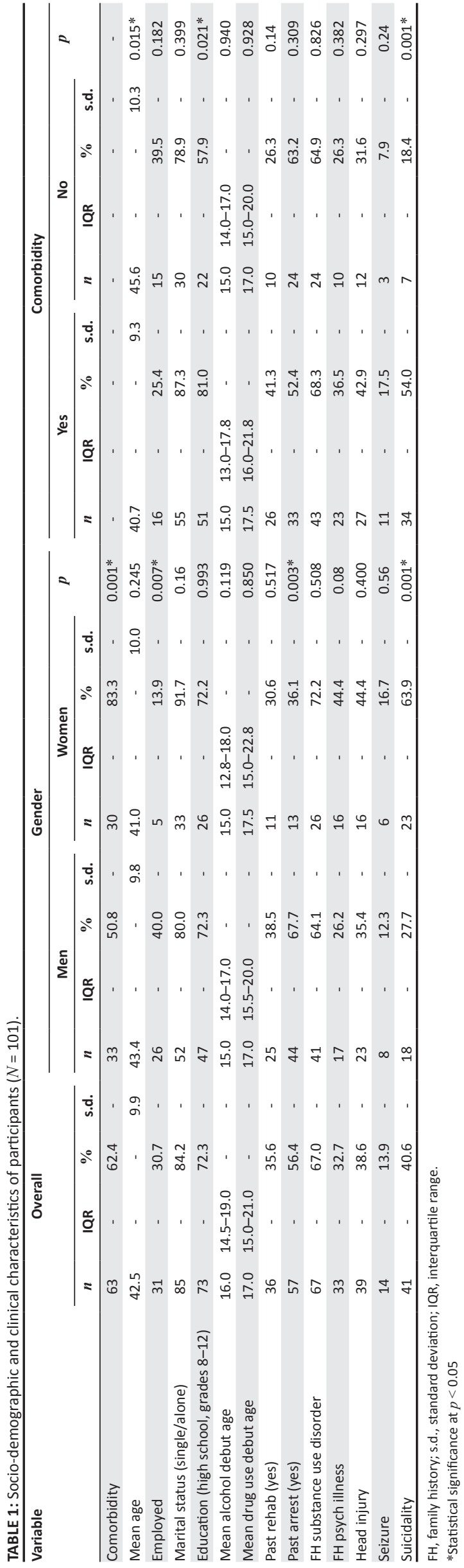

\section{Prevalence of comorbid psychiatric disorders}

Psychiatric comorbidity was identified in 63 (62.4\%) participants, and the proportion was significantly higher in women than in men ( $83.3 \%$ vs. $50.8 \%, p=0.001)$. As shown in Table 1, the groups with and without comorbidities did not differ in most of the socio-demographic variables, but the former were significantly more likely to be younger ( $41 \mathrm{vs.} 46$ years), educated to high school level ( $81.0 \%$ vs. $57.9 \%)$ and admitted to suicidal ideation (54.5\% vs. $18.4 \%)$. Overall, women were more likely to have suicidal thoughts than men (63.9\% vs. $27.7 \% ; p=0.001)$.

Of those with comorbidity, 28 (44.4\%) had one disorder, 35 $(55.6 \%)$ had 2 or more and none had more than 4 disorders (Table 2).

\section{Types of psychiatric comorbidities}

Mood and anxiety disorders were the most common comorbidities (Table 3). Major depressive disorder was the predominant mood disorder, while agoraphobia, social phobia and generalised anxiety were the most frequent anxiety disorders. The majority of participants with comorbid psychiatric disorders smoked cigarettes or used tobacco $(n=46)$. Some participants experimented with cannabis $(n=23)$ and stimulants $(n=4)$. Only 13 participants met criteria for other substance use disorders.

The proportions of men and women with mood and anxiety disorders did not differ significantly (Table 4). Current or past dependence on substances other than alcohol was

TABLE 2: Number of psychiatric disorders in total population $(N=101)$.

\begin{tabular}{lcc}
\hline Number of comorbid diagnoses & $\boldsymbol{n}$ & $\boldsymbol{\%}$ \\
\hline 0 & 38 & 37.6 \\
1 & 28 & 27.7 \\
2 & 21 & 20.8 \\
3 & 9 & 8.9 \\
4 & 5 & 5.0 \\
\hline
\end{tabular}

TABLE 3: Frequencies of different psychiatric disorders among patients with comorbidity $(N=63)$.

\begin{tabular}{lcc}
\hline Psychiatric diagnosis & \multicolumn{2}{c}{ Frequency of diagnosis } \\
\cline { 2 - 3 } & $\boldsymbol{n}$ & $\%$ \\
\hline Mood disorders & 39 & 61.9 \\
MDD & 30 & 76.9 \\
Bipolar & 8 & 20.5 \\
Dysthymia & 1 & 2.6 \\
Anxiety disorders & 43 & 68.3 \\
Agoraphobia (no history of PD) & 10 & 23.3 \\
Social phobia & 10 & 23.3 \\
GAD & 9 & 20.9 \\
PTSD & 9 & 20.9 \\
Panic disorders & 4 & 9.4 \\
OCD & 1 & 2.3 \\
Other substance use disorder & 13 & 20.6 \\
Personality disorders & & \\
Antisocial personality disorder & 10 & 15.9 \\
Psychotic disorders & 2 & 3.2 \\
Eating disorders & 1 & 1.6 \\
\hline
\end{tabular}

MDD, major depressive disorder; PD, panic disorder; GAD, generalised anxiety disorder; PTSD, post-traumatic stress disorder; OCD, obsessive-compulsive disorder. 
TABLE 4: Selected profile of participants with psychiatric comorbidity.

\begin{tabular}{|c|c|c|c|c|c|c|c|c|c|c|}
\hline \multirow[t]{3}{*}{ Variable } & \multirow{2}{*}{\multicolumn{3}{|c|}{ Overall $(n=63)$}} & \multicolumn{6}{|c|}{ Gender } & \multirow[t]{3}{*}{$p$} \\
\hline & & & & \multicolumn{3}{|c|}{ Men $(n=33)$} & \multicolumn{3}{|c|}{ Women $(n=30)$} & \\
\hline & $n$ & $\%$ & s.d. & $n$ & $\%$ & s.d. & $n$ & $\%$ & s.d. & \\
\hline Mean age in years & 40.7 & - & 9.3 & 41.4 & - & 9.6 & 39.9 & - & 9.0 & 0.535 \\
\hline Education (high school) & 51 & 81 & - & 27 & 81.8 & - & 24 & 80.0 & - & 0.854 \\
\hline Mean alcohol debut age & 17.1 & - & 5.8 & 15.5 & - & 3.5 & 18.9 & - & 7.2 & 0.024 \\
\hline Mean drug debut age & 19.5 & - & 6.3 & 18.3 & - & 3.4 & 20.7 & - & 8.2 & 0.265 \\
\hline Mood disorder & 24 & 38.1 & - & 13 & 39.4 & - & 11 & 36.7 & - & 0.824 \\
\hline Anxiety disorder & 30 & 47.6 & - & 19 & 57.6 & - & 11 & 36.7 & - & 0.097 \\
\hline Major depression & 37 & 58.7 & - & 18 & 54.5 & - & 19 & 63.3 & - & 0.479 \\
\hline Antisocial & 10 & 15.9 & - & 7 & 21.2 & - & 3 & 10.0 & - & 0.224 \\
\hline
\end{tabular}

s.d., standard deviation.

reported in 13 (12.9\%) participants. Furthermore, 10 (9.9\%) had antisocial personality disorder and only $3(3.0 \%)$ had a psychotic or eating disorder.

\section{Discussion}

The major findings of this study document the high rates $(62.4 \%)$ of psychiatric comorbidity at the only public ARU in the Western Cape, South Africa. To our knowledge, this study represents the first analysis of AUD comorbidity with other mental disorders in an alcohol treatment setting in South Africa. Rates reported elsewhere vary widely from $46.0 \%$ to $92.0 \%$ depending on the settings or patient population, assessment tools used and timing of the diagnostic interviews cognisant of withdrawal effects. ${ }^{2,4,5,21}$ A study conducted in Kerala, India, reported a prevalence of $66.59 \%$, which is comparable to the present study. ${ }^{22}$

Mood and anxiety disorders were the most frequent comorbidities, and more than half of the total sample had two or more individual disorders. The prominence of mood, anxiety, substance use and antisocial disorders in this study is similar to that reported in past studies, ${ }^{4,5,21,22}$ and is consistent with the pattern reported for the general South African population. ${ }^{13}$ Various models have been proposed to explain the high comorbidity between AUDs and mood and anxiety disorders and have included, among others, a causal relationship, cognitive bias or shared risk because of psychopathology during childhood. . $3,24,25,26^{2}$

Only three cases of psychotic and/or eating disorders were identified in the present study that likely reflects the low community prevalence of these disorders. However, it is possible that patients with AUD with these conditions were receiving treatment elsewhere, that is, within the general psychiatry department or eating disorder unit. Similar to other studies,,$^{27,28}$ a substantial proportion of participants $(56.0 \%)$ in the present study had multiple psychiatric diagnoses, which demonstrates the heterogeneity of comorbidity in AUD populations and emphasises the importance of exhaustive assessment.

The preponderance of males in our sample (64.0\%) has also been noted in other treatment-seeking samples. ${ }^{29}$ The observation emphasises the previously acknowledged underuse of alcohol treatment programmes by women, which is often because of factors related to greater stigma associated with alcohol use compared with men as well as socio-economic factors such as child care and concerns about child custody issues. . $^{30,31,32}$

However, the proportion of women with comorbidity was much higher than men (83.0\% vs. $51.0 \%$ in men), with significantly higher rates of mood and anxiety disorders in women. Mood and anxiety disorders are generally more common in women in both alcohol-dependent and nondependent cohorts. $33,34,35,36$ It has been hypothesised that the motivation for drinking in women is more likely to self-treat emotional difficulties, including depression and anxiety, while men are more likely to drink for effect or in response to peer pressure. ${ }^{34}$

A worrisome finding was the high prevalence of suicidality in the entire sample $(41.0 \%)$ and, particularly, in women with additional psychopathology (70.0\%). For alcoholics, being female and having depression are associated with an increased number of suicide attempts. ${ }^{37}$ Out of every 10 women, 8 had an additional psychiatric disorder and 6 of these had suicidal tendencies. Females are, therefore, a particularly vulnerable group in this context and need to be assessed accordingly.

Our participants with comorbidity were younger and likely to have more years of schooling compared to participants without comorbidity. It is possible that patients with comorbidity experience problems from alcohol use sooner and, therefore, present to our service at younger age or are referred sooner. Furthermore, better educated people may be more aware and responsive to their symptoms or may be more resourceful in negotiating access to treatment services and, therefore, more likely to seek treatment. ${ }^{38}$

Overall, psychiatric comorbidity has important clinical implications for patients with AUDs as it generally predicts poorer treatment outcomes., ${ }^{1,39}$ Therefore, the high prevalence found in this study is important because many programmes have limited access to mental health workers. This study highlights the need to employ staff with skills to recognise and treat psychiatric comorbidity in programmes that treat patients with AUD.

This study has several limitations. Firstly, patients who had been admitted but did not participate because they had 
self-discharged during the first week, who were not present in the unit at the time of recruitment because of a transfer for medical treatment, or who did not meet inclusion criteria may have influenced findings. Secondly, although mood and anxiety disorders (the major comorbid categories in this study) are more likely to precede the onset of alcohol addiction, at least in women, ${ }^{13}$ the precise temporal sequence, aetiology and course of the disorders in the context of the substance use disorder cannot be established in this cross-sectional study. Thirdly, community studies often report lower rates of comorbidity compared to studies involving treatment-seeking patients - a finding interpreted to indicate that the burden of additional comorbidities may be a motivation to seek treatment. ${ }^{40}$ Therefore, the rates of psychiatric disorders reported here, while providing useful indications, may not be representative of community settings. Fourthly, we assessed and reported suicidal risk broadly in a manner that has limited application in clinical practice. Future studies should delineate levels of risk, including suicidal ideation, suicidal behaviour and impulsivity, to provide more useful information for therapy and risk stratification.

\section{Conclusion}

The results indicate that psychiatric multi-comorbidity is common at this ARU, particularly among the women. This study underlines the importance of screening for suicidality and psychiatric disorders, and the need for subsequent appropriate management as an essential part of treatment planning to enhance treatment outcomes in patients with AUDs. Targeted interventions aimed at preventing and treating these disorders in women should also be considered a priority.

\section{Acknowledgements}

The authors acknowledge help from Michael McCaul (Centre for Evidence-Based Health Care, Stellenbosch University) with data analysis and also thank the nursing staff and patients at the ARU, Stikland Hospital, for assistance during data collection and for agreeing to participate in the study, respectively. They acknowledge Karis Moxley (Department of Psychiatry, Stellenbosch University) for writing assistance and technical editing.

\section{Competing interests}

The authors declare that they have no financial or personal relationship(s) that may have inappropriately influenced them in writing this article.

\section{Authors' contributions}

C.M.G. and L.W. conceived the study, and all the authors contributed to the design. C.M.G. collected the data and produced early drafts of the manuscript. M.M. analysed the data and critically reviewed the manuscript. All authors contributed to the interpretation of results, discussion, reviewing of the drafts and approval of the final manuscript.

\section{References}

1. Kessler RC. The epidemiology of dual diagnosis. Biol Psychiatry. 2004;56:730-737. https://doi.org/10.1016/j.biopsych.2004.06.034

2. Hasin DS, Stinson FS, Ogburn E, Grant BF. Prevalence, correlates, disability, and comorbidity of DSM-IV alcohol abuse and dependence in the United States: Results from the National Epidemiologic Survey on alcohol and related conditions. Arch Gen Psychiatry. 2007;64(7):830-842. https://doi.org/10.1001/archpsyc.64.7.830

3. Regier DA, Farmer ME, Rae DS, et al. Comorbidity of mental disorders with alcohol and other drug abuse. Results from the Epidemiologic Catchment Area (ECA) study. JAMA. 1990;264(19):2511-2518. https://doi.org/10.1001/jama.1990.03450190043026

4. Vohra AK, Yadav BS, Khurana H. A study of psychiatric comorbidity in alcohol dependence. Indian J Psychiatry. 2003;45:247-250.

5. Mann K, Hintz T, Jung M. Does psychiatric comorbidity in alcohol-dependent patients affect treatment outcome? Eur Arch Psychiatry Clin Neurosci. 2004;254(3):172-181. https://doi.org/10.1007/s00406-004-0465-6

6. Koob GF, Le Moal M. Drug addiction, dysregulation of reward, and allostasis. Neuropsychopharmacology. 2001;24(2):97. https://doi.org/10.1016/S0893-133X (00)00195-0

7. Anthenelli RM, Schuckit MA. Affective and anxiety disorders and alcohol and drug dependence: Diagnosis and treatment. J Addict Dis. 1993;12(3):73-87. https:// doi.org/10.1300/J069v12n03_07

8. Sheehan MF. Dual diagnosis. Psychiat Quar. 1993;64(2):107-134. https://doi. org/10.1007/BF01065865

9. Cargiulo T. Understanding the health impact of alcohol dependence. Am J Health Syst Pharm. 2007;64(5 Suppl 3):S5-S11. https://doi.org/10.2146/ajhp060647

10. Curran GM, Sullivan G, Williams K, Han X, Allee E, Kotrla KJ. The association of psychiatric comorbidity and use of the emergency department among persons with substance use disorders: An observational cohort study. BMC Emerg Med. 2008;8(1):1-6. https://doi.org/10.1186/1471-227X-8-17

11. Martín-Santos R, Fonseca F, Domingo-Salvany A, et al. Dual diagnosis in the psychiatric emergency room in Spain. Eur J Psychiatry. 2006;20(3):147-156. https://doi.org/10.4321/S0213-61632006000300002

12. Sterling S, Chi F, Hinman A. Integrating care for people with co-occurring alcohol and other drug, medical, and mental health conditions. Alcohol Res Health 2011;33(4):338-349.

13. Williams DR, Herman A, Stein DJ, et al. Twelve-month mental disorders in South Africa: Prevalence, service use and demographic correlates in the populationbased South African Stress and Health Study. Psychol Med. 2008;38(2):211-220. https://doi.org/10.1017/S0033291707001420

14. World Health Organization. Global status report on alcohol and health [homepage on the Internet]. c2014 [cited 2017 Feb 18]. Available from: http://apps.who.int/ iris/bitstream/10665/112736/1/9789240692763_eng.pdf

15. Herman AA, Stein DJ, Seedat S, Heeringa SG, Moomal H, Williams DR. The South African Stress and Health (SASH) study: 12-month and lifetime prevalence of common mental disorders. S Afr Med J. 2009;99(5 Pt 2):211-220.

16. Saban A, Flisher AJ, Grimsrud A, et al. The association between substance use and common mental disorders in young adults: Results from the South African Stress and Health (SASH) survey. Pan Afr Med J. 2014;17(Suppl 1):11.

17. Saban A, Flisher A, Laubscher R, London L, Morojele N. The association between psychopathology and substance use: Adolescent and young adult substance users in inpatient treatment in Cape Town, South Africa. Pan Afr Med J. 2014; 17(Suppl 1):18.

18. Weich L, Pienaar W. Occurrence of comorbid substance use disorders among acute psychiatric inpatients at Stikland Hospital in the Western Cape, South Africa. Afr J Psychiatry. 2009;12(3):213-217. https://doi.org/10.4314/ajpsy. v12i3.48496

19. Abler LA, Sikkema KJ, Watt MH, et al. Longitudinal cohort study of depression, post-traumatic stress, and alcohol use in South African women who attend alcohol serving venues. BMC Psychiatry. 2014;14(1):224. https://doi.org/10.1186/ s12888-014-0224-9

20. Sheehan D, Lucrubier Y, Sheehan KH, et al. The Mini-International Neuropsychiatric Interview (MINI): the development and validation of a structured diagnostic psychiatric interview for DSM-IV and ICD-10. J Clin Psychiatry. 1998;59(20):22-33.

21. Singh NH, Sharma SG, Pasweth AM. Psychiatric co-morbidity among alcohol dependants. Indian J Psychiatry. 2005;47(4):222-224. https://doi.org/10.4103/0019-5545.43058

22. Kattukulathil S, Kallivayalil RA, George R, Kazhungil F. Psychiatric comorbidity in alcohol dependence: A cross-sectional study in a tertiary care setting. Kerala J Psychiatry. 2015;28(2):156-160.

23. Boschloo L, Vogelzangs $\mathrm{N}$, Smit JH, Veltman DJ, Beekman AT, Penninx BW. Depressive and anxiety disorders predicting first incidence of alcohol use disorders: Results of the Netherlands Study of Depression and Anxiety (NESDA). J Clin Psychiatry. 2013;74(12):1233-1240. https://doi.org/10.4088/ JCP.12m08159

24. Pasche $\mathrm{S}$. Exploring the comorbidity of anxiety and substance use disorders. Curr Psychiatry Rep. 2012;14(3):176-181. https://doi.org/10.1007/s11920-012 0264-0

25. Boden JM, Fergusson DM. Alcohol and depression. Addiction. 2011;106(5): 906-914. https://doi.org/10.1111/j.1360-0443.2010.03351.x

26. Flensborg-Madsen T. Alcohol use disorders and depression - The chicken or the egg? Addiction. 2011;106(5):916-918. https://doi.org/10.1111/j.13600443.2011.03406.x 
27. Van Emmerik-van Oortmerssen K, Van de Glind G, Koeter MW, et al. Psychiatric comorbidity in treatment-seeking substance use disorder patients with and comorbidity in treatment-seeking substance use disorder patients with an without attention deficit hyperactivity disorder: Results of the

28. Chen KW, Banducci AN, Guller L, et al. An examination of psychiatric comorbidities as a function of gender and substance type within an inpatient substance use treatment program. Drug Alcohol Depend. 2011;118(2):92-99. https://doi. org/10.1016/j.drugalcdep.2011.03.003

29. Rincon-Hoyos HG, Castillo A, Prada SI. Alcohol use disorders and psychiatric diseases in Colombia. Colomb Med (Cali). 2016;47(1):31-37.

30. Green CA. Gender and use of substance abuse treatment services. Alcohol Res Health. 2006;29(1):55-62.

31. Greenfield SF, Brooks AJ, Gordon SM, et al. Substance abuse treatment entry retention, and outcome in women: A review of the literature. Drug Alcoho Depend. 2007;86(1):1-21. https://doi.org/10.1016/j.drugalcdep.2006.05.012

32. Weisner C SL. Gender disparities in treatment for alcohol problems. JAMA 1992;268:1872-1876. https://doi.org/10.1001/jama.1992.03490140080039

33. Eaton NR, Keyes KM, Krueger RF, et al. An invariant dimensional liability model of gender differences in mental disorder prevalence: Evidence from a national sample. J Abnorm Psychol. 2012;121(1):282-288. https://doi.org/10.1037/a0024780
34. Payne RA, Back SE, Wright T, Hartwell K, Brady KT. Alcohol dependence in women: Comorbidities can complicate treatment. Curr Psychiatr. 2009;8(6):52-59.

35. Brady KT, Grice DE, Dustan L. Gender differences in substance use disorders. Am J Psychiatry. 1993;150:1707-1711. https://doi.org/10.1176/ajp.150.11.1707

36. Helzer JE PT. The co-occurrence of alcoholism with other psychiatric disorders in the general population and its impact on treatment. J Stud Alcohol. 1988;49(3) 219-224. https://doi.org/10.15288/jsa.1988.49.219

37. Conner KR, Hesselbrock VM, Meldrum SC, et al. Transitions to, and correlates of, suicidal ideation, plans, and unplanned and planned suicide attempts among 3,729 men and women with alcohol dependence. J Stud Alcohol Drugs. 2007;68(5):654-662. https://doi.org/10.15288/jsad.2007.68.654

38. Rosenstock IM. Why people use health services. Milbank Q. 2005;83(4):1-32 https://doi.org/10.1111/j.1468-0009.2005.00425.x

39. O'Brien CP, Charney DS, Lewis L, et al. Priority actions to improve the care of persons with co-occurring substance abuse and other mental disorders: A call to action. Biol with co-occurring substance abuse and other mental disorders: A call to action.
Psychiatry. 2004;56:703-713. https://doi.org/10.1016/j.biopsych.2004.10.002

40. Kaufmann C, Chen L, Crum R, Mojtabai R. Treatment seeking and barriers to treatment for alcohol use in persons with alcohol use disorders and comorbid mood or anxiety disorders. Soc Psychiatry Psychiatr Epidemiol. 2014;49(9): 1489-1499. https://doi.org/10.1007/s00127-013-0740-9 